\title{
The New Jersey Environmental Information Network: Providing Access to New Jersey's Environmental Literature
}

\begin{abstract}
Introduction
The environmental situation in New Jersey is complex. The state is replete with areas tremendous natural beauty: pristine beaches and sand dunes, lush green countryside, historic towns, rolling hills, scenic river valleys and mountain overlooks, lush wetlands, and dense pine forests. By many measures, however, New Jersey is the most polluted of the United States' fifty states, and its environmental heritage is undermined by past and present treatment of the environment. Efforts to remediate environmental damage resulting from New Jersey's industrial history and current industrial practices, and attempts to preserve open space through intelligent management of future development, have resulted in a tremendous amount of scientific study within the state. However many, perhaps most, of the resulting research reports are unpublished, elusive, and unavailable for secondary research purposes.
\end{abstract}

This paper will outline the efforts of a partnership in New Jersey to make environmental information widely and readily available. In addition to discussing the project's background and implementation, we will cover in some detail the technological considerations for creating a webbased product that will be used to manage and query diverse information types. This discussion will include: determining system architecture and requirements, database design and programming, design of user interface and graphical design for web accessibility, and need for awareness of and compliance with current information technology standards. These are general issues, which all producers of end-user information systems must address.

More specifically, this paper will discuss the technological issues involved in building a database based on a topical and geographical approach to information management. The New Jersey Environmental Information Network is neither a digital library nor a traditional catalog/index to information; it is a hybrid of both, and it encompasses all available media and formats important to the study of the environment. The NJEIN contents range from print inventories of species within a geo-region to directory information about local experts to digital models and GIS layers. The hybrid nature of the product has given rise to some unusual data management issues.

Project Description:

The New Jersey Environmental

by Ron Jantz

Linda Langschied *
Information Network (NJEIN) is a prototype of a web-based environmental information system for New Jersey ecosystems. The authors' participation in this project is as members of the New Jersey Ecological Research Partnership, a group of academic, non-profit, and corporate organizations concerned with making scientific information on the environment available to all potential users. Special emphasis is placed on making scientific research available to enable sound decision-making processes within the state.

The specific goals of the Partnership include:

- developing consistent, quality assured data and data dissemination mechanisms;

- promoting involvement of the public in data collection, utilization, and education,

- promoting mechanisms to facilitate transfer, access and use of environmental information.

The NJEIN was envisioned by the Partnership as the appropriate mechanism for realizing these goals. Working with New Jersey's Department of Environmental Protection and Rutgers' Ecopolicy Center the authors, representing Rutgers University Libraries' Scholarly Communication Center, have received support to develop a first version of the prototype. A conceptual description of the NJEIN would include these essential elements:

1. NJEIN will serve as an electronic clearinghouse of information about the New Jersey environment that can be queried by location, topic, or both.

2. It encompasses all topic-relevant information, regardless of physical format.

3. The system provides retrieval of located sources through:

a) downloading of data;

b) "scan-on-demand" system for non-digital objects (fee-based); 
c) web links where available;

d) referral to a physical repository where appropriate.

4. The NJEIN will grow as items are entered into the database by data holders/producers, rather than by librarians/information managers.

5. NJEIN's structure (both intellectual and technological) reflects an emerging concept of "placebased management" which is being embraced by multiple federal and state agencies; it also acknowledges the naturally-occuring approach to environmental studies that scientists and other researchers employ. The importance of place-based information organization is particularly manifested in the prominence of GIS usage by environmental researchers. Therefore we determined that all items entered into the database, whether digital or nondigital, will be geo-located and thereby retrievable by geographic query of the database.

6. Because of the foregoing, and in order to accommodate the GIS data layers produced by the New Jersey Department of Environmental Protection and others, the NJEIN will utilize the FGDC metatdata standard for descriptive cataloging of items in the database.

7. Particular emphasis is given to capturing the abundance of "gray" literature and data that is produced in the state, often through project-specific research done by consultants, and making it available for secondary research.

New Role of Librarians in Information Systems Design: The development of the NJEIN in a library setting illustrates the rapidly changing role of librarians in providing information access to electronic information. A decade ago, electronic information service librarians acted as the intermediary between patrons and remote, commanddriven databases; with the advent of end-user systems, librarians became coaches to hands-on users. New tools and, perhaps even more importantly, new institutional imperatives (in particular, the impetus to create digital libraries) have contributed to reshaping the librarian role yet again, with librarians entering the picture earlier in the process as participants in creation of electronic products.

Developing the NJEIN, an electronic information tool intended for all levels of research from a diverse user community, requires an application of technology that is sophisticated enough to satisfy expert scientific inquiry, yet friendly enough for the interested citizen. The New Jersey Ecological Research Partnership elected to seek librarians, rather than systems programmers, to lead the project's design and development in the belief that technology is only as good as a deep understanding of the needs of its users. Using this interpretation, the field of librarianship does embody numerous characteristics that are essential to assuring quality development of this kind of product. Among them are:

1. Direct experience in user services: Librarians employed in public services and collection development have a demonstrated understanding of what kinds of data users seek, and they strategies they employ in information seeking.

2. Experience with information needs of a diverse audience: The Project's primary intended audience is those officials in New Jersey (e.g., municipal and county administrators, planning boards) who are charged with local decision-making that could effect the environment. But a corollary goal is to make the same information available to those people who might influence government decision-makers: New Jersey's scientists, students, and citizens. Librarians are accustomed to working with a diversity of users, and could anticipate and account for differing levels of user skill in accessing information, particularly in designing a user interface for both entering and searching the database.

3. Technological skills: While these skills could have been obtained from other sources, as noted above, the project leaders among the Partnership (scientists from the Department of Environmental Protection and Ecopolicy Center) expressed great concern that systems programmers might not have adequate knowledge of or sensitivity to end-user needs. Therefore, their preference was that information specialists would take the lead in bringing the project online. Fortunately, recent organizational and technological developments in Rutgers University Libraries ensured that the Library is prepared to undertake the development projects like NJEIN. In particular, the creation of the Scholarly Communication Center (SCC) within Alexander Library, Rutgers' graduate library for social science and humanities research, provided a foundation for digital initiatives.

\section{Placing the Project: the Scholarly Communication Center}

It was, in fact, the Scholarly Communication Center which drew the original Partners to the Rutgers libraries. In order to meet the dual requirement of user-orientation design and sophisticated technological application, the Partnership sought to join forces with librarians adept in both areas. Ultimately, they were referred to the librarians involved with planning Rutgers University Libraries' Scholarly Communication Center (SCC). The SCC, officially opened in October 1998, is a technological research, teaching and learning center. Its components include:

1. A teleconference lecture hall, which gives presenters 
access to a plethora of multimedia presentation options, has satellite uplink/downlink capabilities, and interactive distance conferencing technology. Locally, this facility allows us to hold meetings among Rutgers three distant campuses; it recently enabled journalists in Poland to "attend" a discussion on contemporary international journalism with faculty from Rutgers School of Communication, Information, and Library Studies.

2. Two hands-on, multimedia infused computer classrooms. The classrooms are used primarily to deliver hand-on instruction, and one lab has distance education capabilities.

3. The Humanities and Social Science Data Center, which serves as the hub for reference services, and for research and development activities for the SCC. The Data Center is intended to serve as a testbed site for creation of new information tools. One of its first projects was to bring online the public opinion polls conducted by Rutgers prestigious Eagleton Institute of Politics.

In making the decision several years ago to raise the $\$ 3$ million dollars to build the SCC, our institution committed itself to a technological future. Creating and maintaining this facility necessitated our hiring of new talents. Thusfar, we have revised open positions to create new placements for an Information Technology Librarian, Data Librarian, humanities computing specialists, and system programmers.

While Rutgers librarians, as members of the faculty, have tremendous autonomy in setting their professional priorities, large projects undertaken by librarians are expected to conform to overall institutional priorities. In evaluating whether to assume the development of the NJEIN as an SCC project, the librarians looked to the Mission Statement of the SCC which includes the following goals:

To serve as a testbed and demonstration site for the application, development and evaluation of electronic resources by:

- $\quad$ Providing opportunities for developing electronic resources, multimedia programs and for handling electronic data, text and images.

- Providing guidance, instruction and training in the development, use and evaluation of electronic resources in all formats.

- Delivering remotely accessible resources in support of the goals of the educational and research mission of the University.

- $\quad$ Fostering specialized projects using resources of particular interest to the Rutgers community and the state of New Jersey.

The development of the NJEIN clearly fit the articulated goals of the SCC, and the decision to join the partnership was made. The SCC would "host" the NJEIN, and its librarians would undertake project development with financial support from the New Jersey Department of Environmental Protection.

\section{Summary}

Our ultimate vision with the NJEIN and similar efforts is to develop focused, domain specific collections that are of specific interest to the Rutgers University community and the citizens of New Jersey. Through these efforts, we hope to impose structure and access methods on a large amount of very useful, but also distributed and uncataloged information.

Traditional librarian skill sets in describing and organizing information, and in providing user education services, as well as new technological ones, are critical to projects such as NJEIN. Nevertheless, many (probably most) libraries will not have all requisite skills in-house, and that is true of this project. Developing the NJEIN is an illustration of the need for collaboration and partnership in order to meet shared goals among diverse stakeholders. In this instance, we refer to the environmental scientists, creators and users of data, and librarians/information technology specialists - all are critical contributors to NJEIN, and its success depends on a continuing partnership. What is at stake is the future of decision and policy making within the state. We are very proud to be a part of a process that will help to preserve New Jersey's environmental heritage.

\section{Designing the NJEIN}

Design Methodology.

It is appropriate to say a few words about our design methodology. Traditional methodologies have generally required a static set of requirements that precede the development phase. This approach frequently assumes that the analyst can somehow anticipate and understand all the complex interactions that might occur in an information retrieval system. Our approach has been to embody the requirements in a prototype which allows us to see the interactions and introduce the product at a very early stage to potential customers. Hence our requirements document is, in effect, the prototype. This approach has enabled a highly interactive and iterative design process in which we might make several changes to the prototype in one day. We have been able to do this and still keep the prototype up and running while students continue to load data into the NJEIN. Many development organizations have found that prototyping is one of the most effective methods for determining system requirements. Finally, we have taken the approach that there is a small design team that controls the design of the system and the database. Systems cannot 
be designed by committee; the design team enters into many discussions about the design in committees, small groups, and one-on-one interactions. The resulting design changes are integrated into the prototype where the team makes final decisions based on user needs, technology available, schedule, and other factors. These approaches have been used in other information retrieval systems (Crawford, 1996) and many other similar product developments.

Although the NJEIN is still in prototype form, our efforts so far have allowed us to learn much about the types of information that will be entered into the database, the user interface, and the definition of the database.

\section{NJEIN Architecture and Platform.}

To a large degree, the SCC is acting as a "technology conduit" into the Library; we want to explore various technologies, use the technology in prototypes and hopefully help promulgate stable technology platforms throughout the various Rutgers University libraries in many useful applications. One of our objectives is to establish a technology platform that can be used repeatedly for similar types of applications such as providing access to a variety of databases on the Web. As our university addresses how it will acquire and deploy digital material (Sewell, 1998), we want to have platforms in place that can be used by librarians and others to provide access to electronic resources. Basically, a platform is a set of identified components that work well together and remain relatively stable over a period of time. This approach allows developers to become experts and the components to be thoroughly tested so that reliability is increased and learning time is decreased. The primary platform components are illustrated in the discussion of the NJEIN architecture below.

The architecture for the NJEIN is relatively simple and is illustrated in Figure 1.

We have incorporated off-the-shelf software that has been frequently used in other database applications in the SCC (e.g., Eagleton Archive, Event scheduling, Microforms database) with the objective of standardizing on software components to minimize maintenance and support efforts. Three basic Web-enabled functions are available: 1) create/ modify the reference database, 2) search/browse the reference database, and 3) retrieve/download the digital document when available (e.g. scanned text document, image, or numeric data). The primary components of the

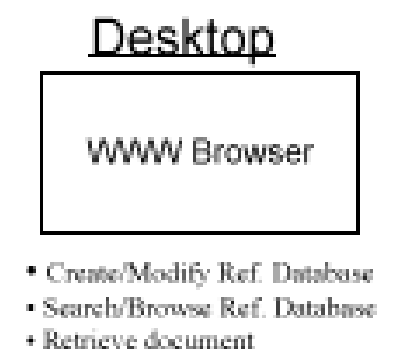

+ Retrieve document
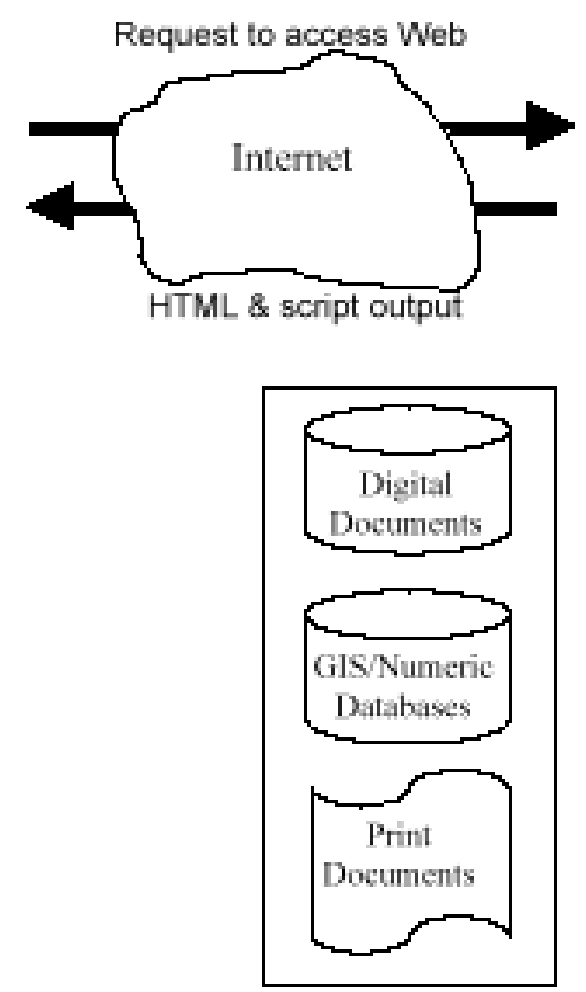

Archive
Server (NT)

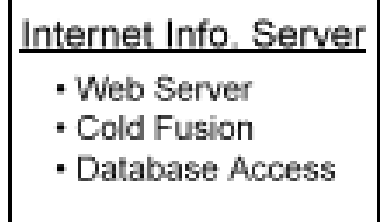

ODBC - MS Acoess

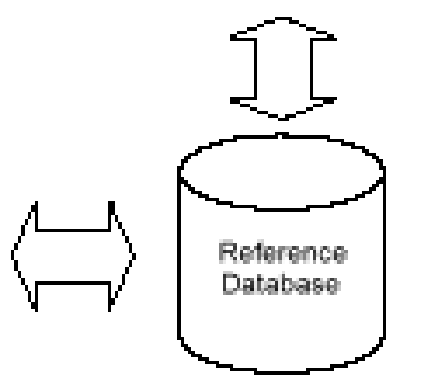

Figure 1 - NJEIN Architecture 
computing and application platform are NT 4.0 with Internet Information Server, FrontPage, Cold Fusion, and MS Access.

Using FrontPage and Cold Fusion, the process of providing database access on the Web is fairly straightforward and can be accomplished simply with SQL statements and without writing a complicated script. From an architectural point of view, the important part of this diagram is the role that Cold Fusion plays in enabling access from the client workstation to the server reference database. The Cold Fusion server processes database requests through the use of templates. The templates are similar to an HTML file with a ".cfm" extension and special CF (cold fusion) tags which the server recognizes while ignoring the regular HTML statements. Using these tags and the SQL query language, one is able to quite easily design web pages that will create database records or alternatively query the database to retrieve information based on a user request. As a result of a database query, output is passed back to the web server from the Cold Fusion server in order to create a dynamic web page. As Figure 1 indicates, we are running Microsoft's Internet Information Server (IIS) which has three major features which make all of this possible: 1) Internet Database Connector (IDC) which provides built-in access to ODBC databases, 2) security integrated with
Windows NT, and 3) ISAPI, a robust high-performance method of communicating with gateway programs (Blum, 1997).

The Reference Database.

\section{Description.}

The Reference Database contains descriptive and access information about the document. Our subject domain is focused on the environment and is geographically limited to New Jersey and surrounding areas (e.g. adjacent states) that might have an impact on the environment of New Jersey. The audience for this database is just about anyone in New Jersey: students, practitioners, scholars, researchers, New Jersey citizens, and decision makers. The medium is primarily print on paper and electronic text and images although other media such as microfilm or video will not be excluded. The document format includes reports, inventories, studies, theses, map images, numeric and GIS data. The domain deals with the sources of data and where and how these data are found, selected and acquired. For the NJEIN, as mentioned previously, we will be focusing on what is sometimes referred to as "gray" literature, or literature that has not been catalogued or indexed

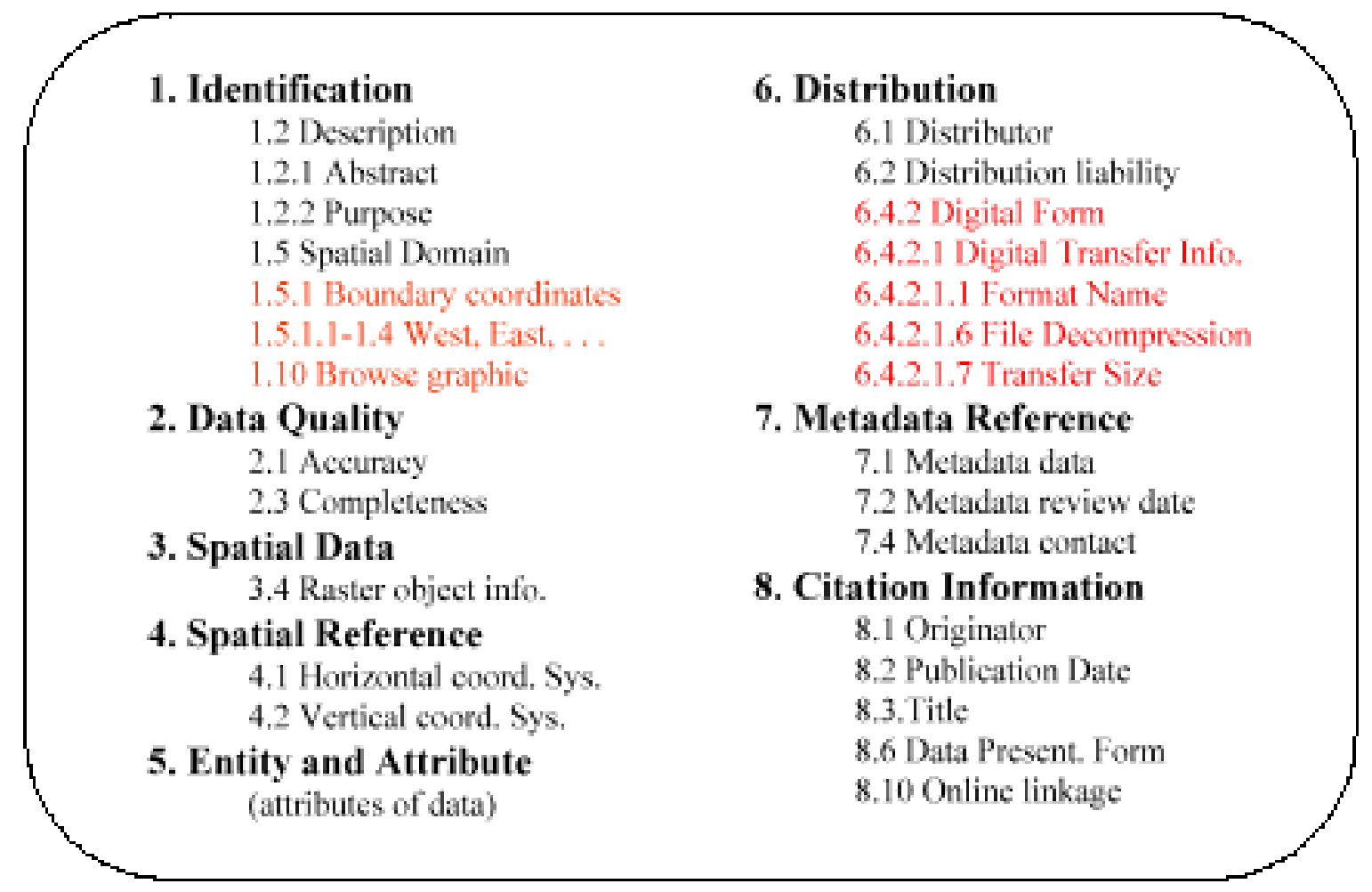

Figure 2 - Major Fields in Reference Database 
previously. Our sources will be primarily universities, institutes, governments at the county and township level, and consultants who do work for New Jersey state and local governments.

\section{Metadata. \\ Definition.}

There are many definitions of metadata and the following operational definition $(\mathrm{Ng}$, et al) highlights the flexibility required in an Internet environment:

\section{Metadata is data which characterizes source data, describes their relationships, and supports its discovery and effective use.}

For our database, we wanted a metadata scheme that was very flexible and would support both intrinsic aspects of the document (e.g. subject, title, etc) and also extrinsic aspects related to administration and non-bibliographic issues such as size or system requirements. Further, we knew that many of our documents would have a geospatial component. Given these requirements, we have decided to use a subset of the Content Standards for Digital Geospatial Data (Federal Geographic Data Committee) for the definition of the reference database. Our reasons for doing this are as follows:

- A subset allows us to have a relatively simple database so that users (non-specialists) will be able to enter data into the Reference Database.

- $\quad$ Using a subset of the FGDC standard will allow us to map our data to other FGDC databases with the objective of being able to exchange data with other organizations and institutions.

- Using the FGDC standard will enable us to take advantage of many of the continuing efforts that are producing related tools such as parsers and compilers.

- We want to be closely aligned with state and federal efforts related to GIS. A 1994 presidential Executive Order has directed federal geographic information to be described using FGDC (Executive Order 12906).

Figure 2 shows some of the key metadata fields in the reference database, organized by major FGDC categories. For example, items in section 6.4 .2 of Figure 2 identify extrinsic aspects of the data whereas sections 1 and 8 contain intrinsic data items.

\section{Accessing the Archive.}

As stated earlier, a major objective of this project is to impose structure and provide convenient access to New Jersey's environmental information. Although pursuing this objective from a librarian's perspective, we are departing from traditional approaches that libraries might take in organizing and cataloging information. As in many endeavors to organize information on the Web (Vellucci, 1997), we do not expect to have exclusive ownership or control of the information resources. Our focus is shifting from ownership to providing access and our "collection" process consists of finding environmental information and developing partnerships with those organizations who do produce and own the data.

This approach lacks the architectural and user interface simplicity of a single, physical OPAC. However, we believe the compromise distributes the effort of maintaining the collection while also improving access. As Vellucci has pointed out, "it is essential and desirable that the confining parameters that define a collection be expanded to accommodate documents that are not owned and physically housed within the library's walls." To accommodate this diverse environment, we have a developed an architecture that has a centralized reference database but may in fact link to other searchable databases, resulting in two tiers of searchable databases.

The NJEIN should provide the ability to not only locate a document but to also retrieve a copy of the specific document. Although we are in the early stages of the prototype, we plan to put considerable effort into making it possible to actually obtain a document (as opposed to just finding a reference to it). As indicated in Figure 1, there are three general types of document formats in the Archive. Print documents will be located at institutions such as Alexander Library Special Collections, the NJ State Library, and designated partner institutions throughout New Jersey. We will enable a user to request a print document electronically through Alexander Library. Frequently requested print documents will be scanned and moved to the digital documents database. Digital documents include both scanned print documents as well as other static documents such as map images. This material will be located on the SCC server and downloadable to a local workstation through standard Web browsers. The third type of archive material is GIS/Numeric databases. The important distinction here is that this digital information is likely to be processed further by a user. For example, numeric data would likely be analyzed using a statistical tool such as SPSS and GIS shape (.shp) files might be used in a GIS tool such as ArcView. It is here that the extrinsic aspects of the metadata become very important such as File Decompression Technique or Transfer Size (see metadata items in Figure 2).

We have taken a pragmatic approach to handling this type of GIS and numeric data. Creating and maintaining GIS databases is a time-consuming and complex process. Our approach is two-fold and recognizes the complexitiy of the data, our partnerships and also the diverse user population. Our townships (Murphy, 1997), counties and states are creating and maintaining a wealth of GIS data. Our 

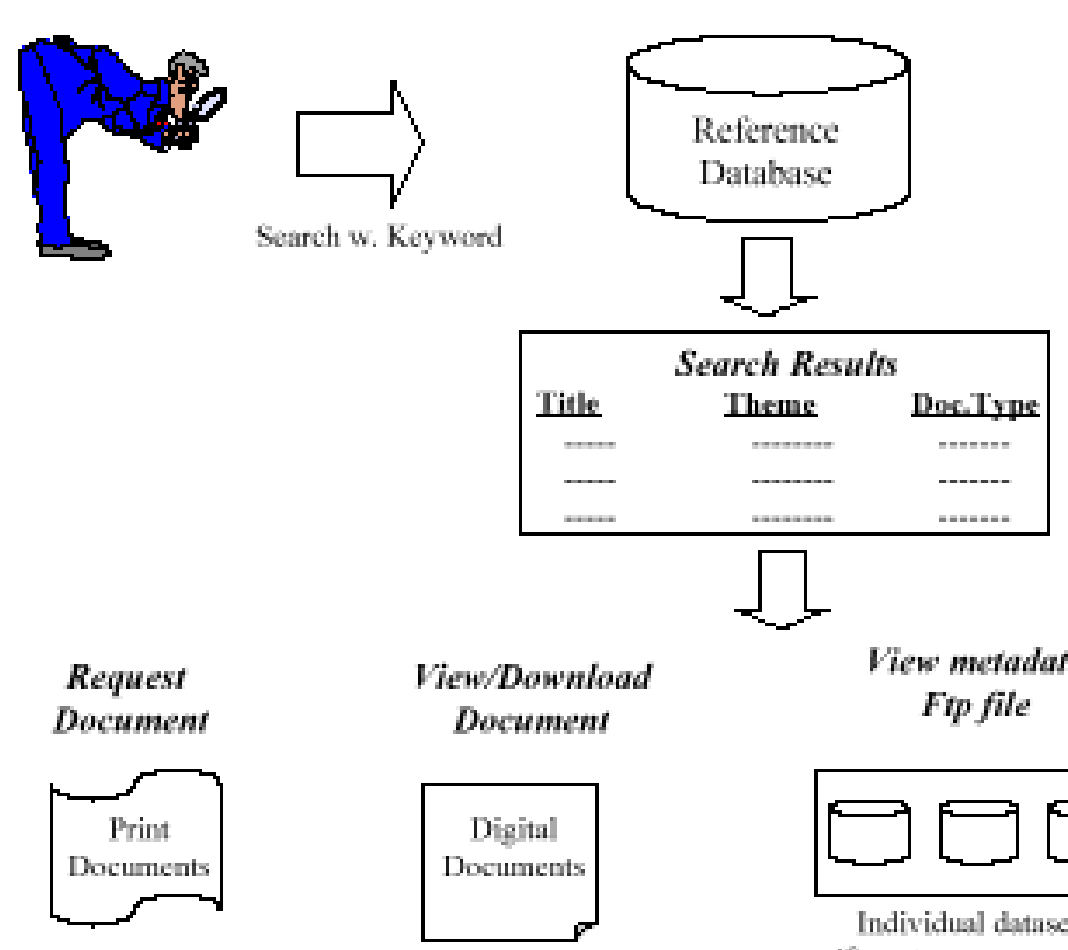

View metadata

Fip file

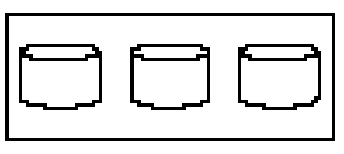

Individual datasets

(from wons, counties)
Search w. Keyword

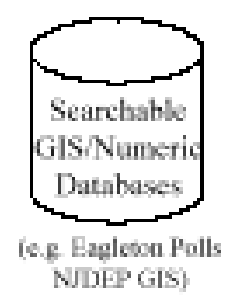

Figure 3 - Reference Database and Archive Relationship

reference database will have an abbreviated record that contains the essential data about the GIS database and points to either the actual document or a search interface so that a prospective user can locate the desired information, understand its content and determine system requirements such as file format and size. Further, where possible we will capture the resulting digital map image, index the image, and place it on the SCC server. This approach has the advantage of making the map images easily available to many of our customers who are not able to deal with GIS data while also having the continuing support of the GIS databases reside in the locations where they are created and maintained. Figure 3 provides an architectural illustration of this approach.

\section{The User Interface - Basic Principles}

Effective user interfaces are extremely difficult to design. The designer has to understand the user of the database, have a good grasp of system design principles, and also be familiar with the subject content. In our project, we will have in the order of 1000's of records (as opposed to 100,000 s) which permits a relatively simple navigation and search structure. We are using the tree structure as shown in Figure 4 below which limits flexibility to some degree but has the advantage of a user interface model that is straightforward and readily understood.

There are a few simple design principles that we have tried to keep in front of us while working on the prototype:

- $\quad$ The user interface should entice and encourage people to want to use the system.

- We will not segment the user community by introducing "advanced" search techniques (i.e. design so that everyone can use all search and browse options).

- $\quad$ There should be many ways to access the subject content and

- $\quad$ Screen display should follow two rules of thumb (Thomson, 1996): 1) No more than $30 \%$ of the screen should be filled with text and 2) The optimum range of options available at any one point is between 5 and 9 .

\section{Opening Screen.}

The opening screen should describe the content, scope, access options, and size of the database (Anderson, 1997). Given the above rules, a major challenge in the opening screen is to present the essentials of content and access without using a large amount of obscure and inappropriate 


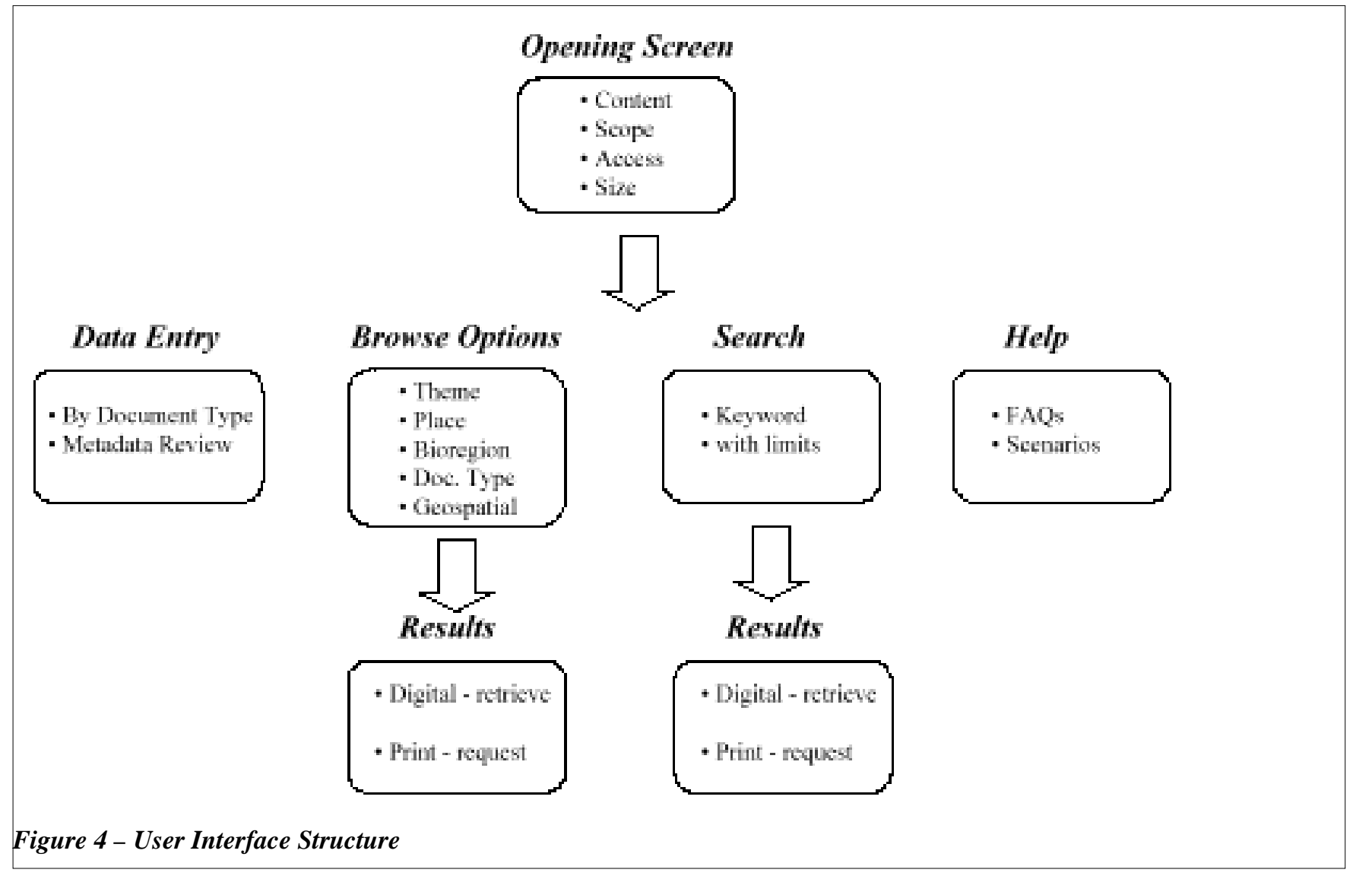

text. Figure 5 provides a representation of the opening screen for the prototype.

\section{Data Entry.}

As has been discussed previously, a unique aspect of the NJEIN is to allow New Jersey citizens and institutions to add data to the collection. To date, librarians and students have been "seeding" the database with relevant documents of all types. Ultimately, we would like to see the NJEIN become self-sustaining by establishing partnerships with institutions, local governments, and citizens by which they would enter environmental data as it becomes available. The data entry screens are relatively straightforward and will not be discussed in detail here. For ease of entry, data entry is performed by selecting a document type such as "'thesis" or "report". This allows us to customize data entry for each type of document and provides a natural context for the user who has the specific type of document in their hands.

In many respects, the NJEIN is a hybrid combining aspects of digital libraries and more conventional OPACs. As mentioned previously, we will have both digital and print documents available. This objective has led us to provide a minimal level of indexing and cataloging as opposed to a database that contains all digital documents and relies on automatic indexing of the entire document for effective retrieval (Witten, et al, 1996). There are two unique aspects to the data entry functions provided in the NJEA.

Creating a Database Record and Controlled Vocabulary. Keeping in mind our objective of enabling users to enter bibliographic data, we have required only a few fields to be entered in each record. For all of our document types, in addition to author or originator, a record also requires entries for title, abstract, primary theme, primary place, and document type. Generally, the title can be taken directly from the document without undue difficulty or user confusion. In terms of traditional cataloging tasks, the abstract will be most difficult for the novice user. Users will, in all likelihood, struggle to accurately and succinctly describe what the document is about. To assist in helping users describe what the document is about we have required three additional fields: primary theme, primary place, and document type. To enter data from these fields, a user selects from a pre-constructed set of themes places, and types. Themes have been selected to describe environmental topics that are specific to the state of New Jersey and places include the states in the Northeast, New Jersey counties, and the bioregions of New Jersey. As an example, Figure 6 shows the screen for "Reports Entry". 


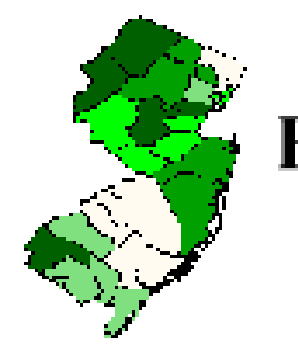

\section{Welcome to the New Jersey Environmental Information Network}

Sponsored by the NJ DEP Division of Science and Research Hosted by Rutgers University Scholarly Communication Center

\section{The NJEIN is an information archive that enables access to a wealth of information about the New Jersey environment. You can browse the archive by theme, place, document type, or bioregion. You can search the archive by keyword with special limits. The NJEIN also invites you to submit your environmental data to the Archive so that it is available to others in New Jersey. A Directory of New Jersey environmental is organizations is also available.}

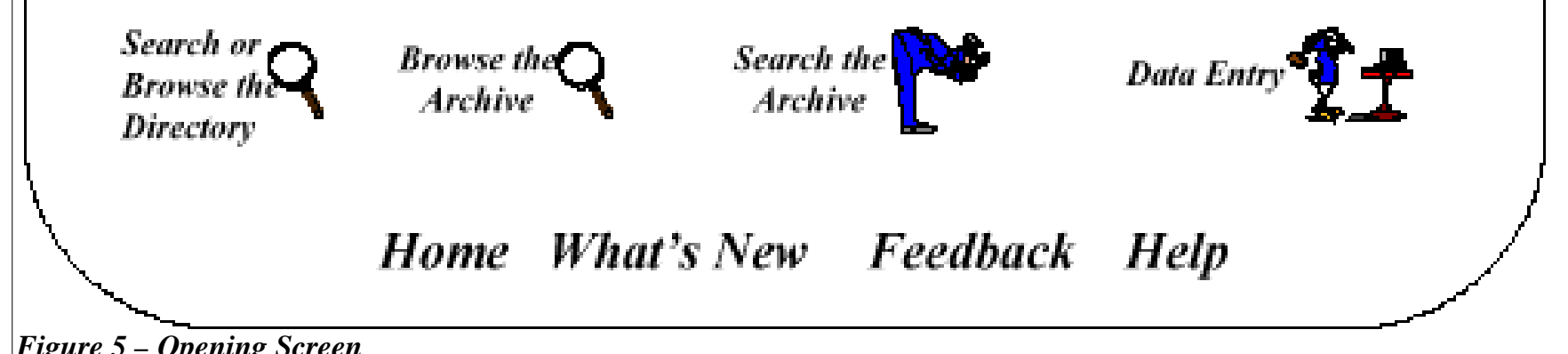

Figure 5-Opening Screen

Our user interface assumes that at least some of the users will be willing to take the time and effort to contribute to the system. Thus, users have the option of entering as many additional theme and place descriptors as appropriate. This process adds the user's knowledge state to the representation process (O’Connor, 1996).

These user interface concepts are all brought together in the single search interface in which a user can use keywords to search across the title, abstract, theme and place fields. These searches can be further limited by selecting from "pick-lists" of primary themes, primary places, and document type. For example, a user may search for "pollution" and limit the search to primary place="Monmouth county" and document type="map".

\section{Metadata Review Process}

The metadata review process is intended to supplement the user process of entering bibliographic data. Each time a user enters a record from the Web, email is sent to a library coordinator. This person is assigned the task of reviewing the record for quality and completeness. Since users are required to enter basic information and can take advantage of the pre-constructed lists, we expect this process to be one of eliminating records that don't make sense or do not provide adequate information as to how to locate and acquire a specific document. The record will not actually be searchable in the database until the librarian has entered a metadata review data (item 7.2 in Figure 2).

Browsing the Reference Database

Browsing is the process of scanning by content or structure and results in an awareness of unexpected or new content and paths in the database (Dodd, 1996). In the NJEIN, we have put considerable emphasis on browsing for several reasons. Our user population is diverse and scattered geographically throughout the state so that it is difficult to educate the user community about subject terms and cataloguing rules. Searching is difficult and, according to researchers, can put undue cognitive load on an uninitiated 


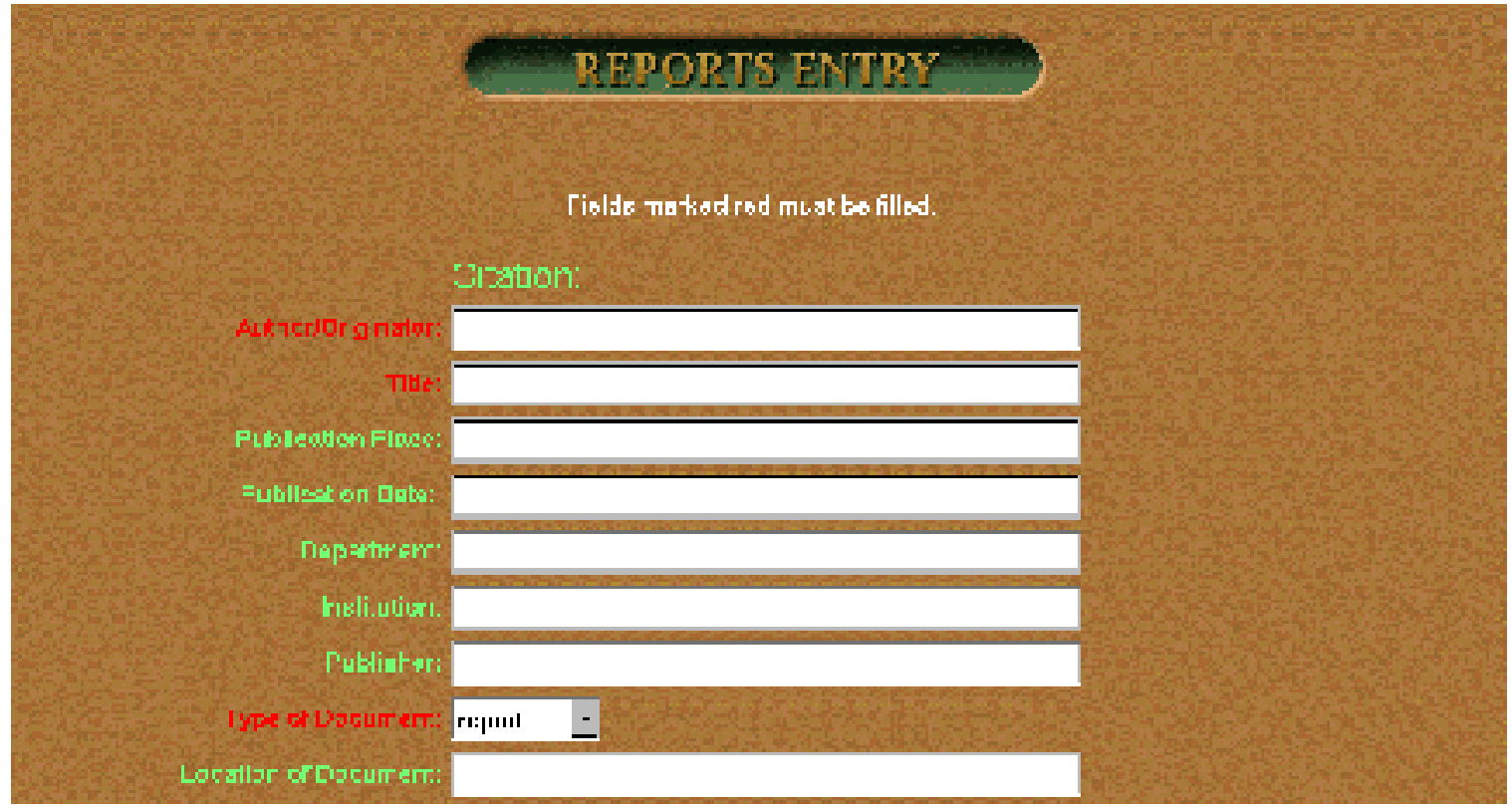

Figure 6-Approaches to Sample Data

user who has to devise search strategies, determine search terms, and grapple with boolean logic (Behesti, et al, 1996). The data shows that between 30 and $45 \%$ of all searches starting in an online database are concluded with browsing library shelves.

Browsing allows the user to become familiar with the database contents and structure without trying to understand the design principles of the information retrieval system.

Our second reason for placing considerable emphasis on browsing stems from a pragmatic system design approach. Browsing lends itself to direct manipulation user interfaces; further our database is in its infancy and sophisticated search capabilities are not yet needed.

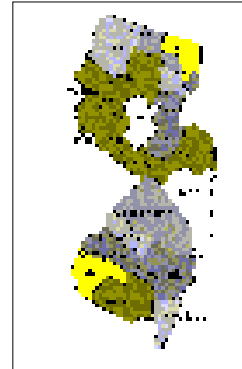

1) Seleet a county

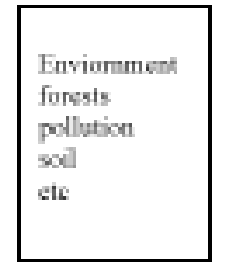

4) Seleet a primary theme
The browsing approach is to provide as many access paths as possible to the database. These paths are summarized in Figure 7:
Figure 7-Approaches to Browsing

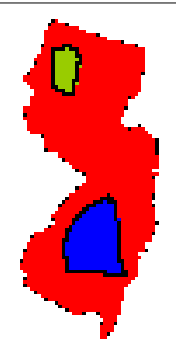

2) Select a biogregion

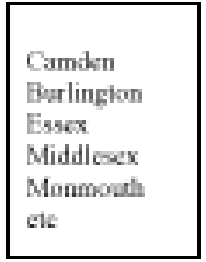

5) Seleet a primary place

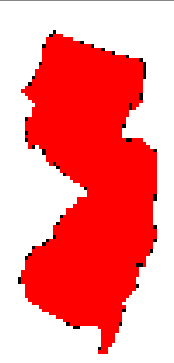

3) Seleet a geospatial area
Inveriory

Map

Thesis

Report

Stady

ete

6) Seleet a document type 


\section{Searching}

After a user has familiarized himself with the database through browsing, he can undertake the more mentally demanding task of searching. In the search process, we have tried to use the knowledge gained through browsing. So, for example, the user can employ the rather straightforward search form as shown below which allows a keyword to be searched across multiple fields (title, abstract, theme, and place). This search process can be further limited by using one of the browse approaches. For example, one might limit the search process to only document types of "map image".

\section{Status and Conclusion}

The NJEIN prototype has served, and for the foreseeable future, will continue to serve its purpose well. Through its development, the authors have gained critical knowledge and experience that will inform the creation of future products. Discovery and entry of scientific information into the database is ongoing, and attendant administrative tasks and processes are in place. These operations will continue, as they are quite fundamental to the project. However, recent developments on the national environmental level have propelled us into the delivery of environmental information on a much grander scale than originally envisioned. NJEIN as we have envisioned it may not exist, but instead merge with a national priority for environmental information management. In doing so, the NJEIN stands to become a prototype for the rest of the nation's states. We invite our readers to visit the NJEIN website at http://scc01.rutgers.edu/njenvironment and send us feedback.

A recent partnership between the New Jersey Department of Environmental Protection's GIS Division and the federal Environmental Protection Agency has been established to create a national registry of environmental information, the Environmental Information Management System (EIMS). The authors, along with NJ-DEP's GIS officials, represent New Jersey in this initiative. To date, all other participants come from within the EPA's vast bureaucracy. New Jersey is the first, and so far, sole state participant. It is with some regret that in order to participate fully with the national project, we must relinquish some of our own design and administrative control and flexibility. Yet we are convinced that uniformity and interoperability across the various EIMS databases is a worthy aim, intended to take researchers smoothly across the possible points of access to environmental information and so we have become partners again with scientists, researchers, and information managers, this time on a more global scale.

We hope to be able to report to IASSIST again, in not too many years, the status of environmental information systems in New Jersey, and in the nation.

\section{References}

Anderson, J.D. (1997). Indexing for Information Retrieval: The Design of Indexes for Textual Databases. (second

\section{SFARCH AROETVF}

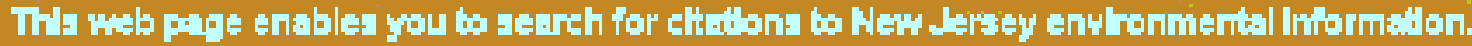

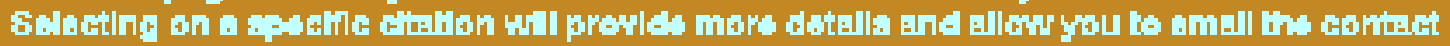
percen, acruming an omall adtreas has ben provldad.
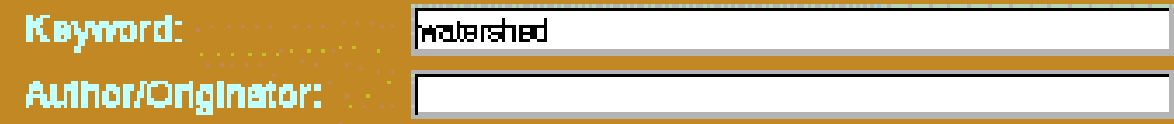

Litht Berioth by:

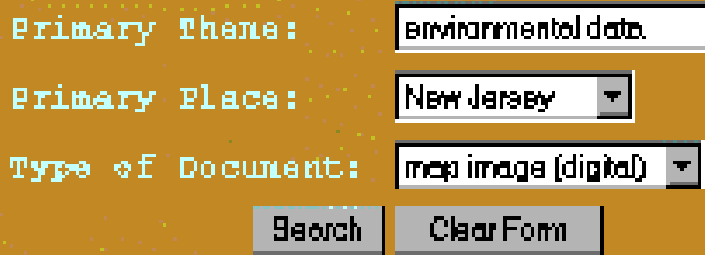

Figure 8 - Searching with Limits 
working draft).

Behesti, J., Large, V. \& Bialek, M. (1996). PACE: A browsable graphical interface. Information Technology and Libraries, 15, (4), $231-240$.

Blum, A. (1997). Active X Web Programming. New York: Wiley Computer Publishing.

Crawford, W. (1996). Developing Eureka: rapid access to very large databases. Information Technology and Libraries, 15, (1), 9-19.

Dodd, D.G. (1996). Grass-roots cataloging and classification: Food for thought from World Wide Web subject oriented hierarchical lists. Library Resources and Technical Services, 40, (3), 275 - 286.

Federal Geographic Data Committee Standards: URL: http://fgdc.er.usgs.gov/Standards/Standards.html.

Murphy, T. (1997/November). How Tewkesbury’s GIS program aids sensible development. New Jersey Municpalities. 72,88.
Ng, Kwong Bor, Park, S. \& Burnett, K. (1997). Control or Mangement: A comparison of the two approaches for establishing metadata schemes in the digital environment. http://www.scils.rutgers.edu/ sypark/asis.html.

O'Connor, B.C. (1996). Explorations in Indexing and Abstracting: Pointing, Virtue and Power. (Chapter 9: pp. 145 - 158). Englewood, CO: Libraries Unlimited.

Thomson, William K. (1996). Designing effective user interfaces. Proceedings of the Seventeenth National Online Meeting. New York: May 14-16. $385-391$.

Sewell, R. (Ed.) (1998). A Bridge to the Future: Rutgers Digital Library Initiative (draft document).

Vellucci, S. (1997). Options for organizing electronic resources: The coexistence of metadata. Bulletin of the American Society for Information Science, 24, (1), 14 - 17.

Witten, I; Cunningham, S. \& Apperly, M. (November/ 1996). The New Zealand Digital Library Project. D-Lib Magazine. http://www.dlib.org/dlib/november96/ newzealand/11witten.html

* Paper presented at the annual IASSIST Conference, New Haven Connecticut, May 19-22, 1998.

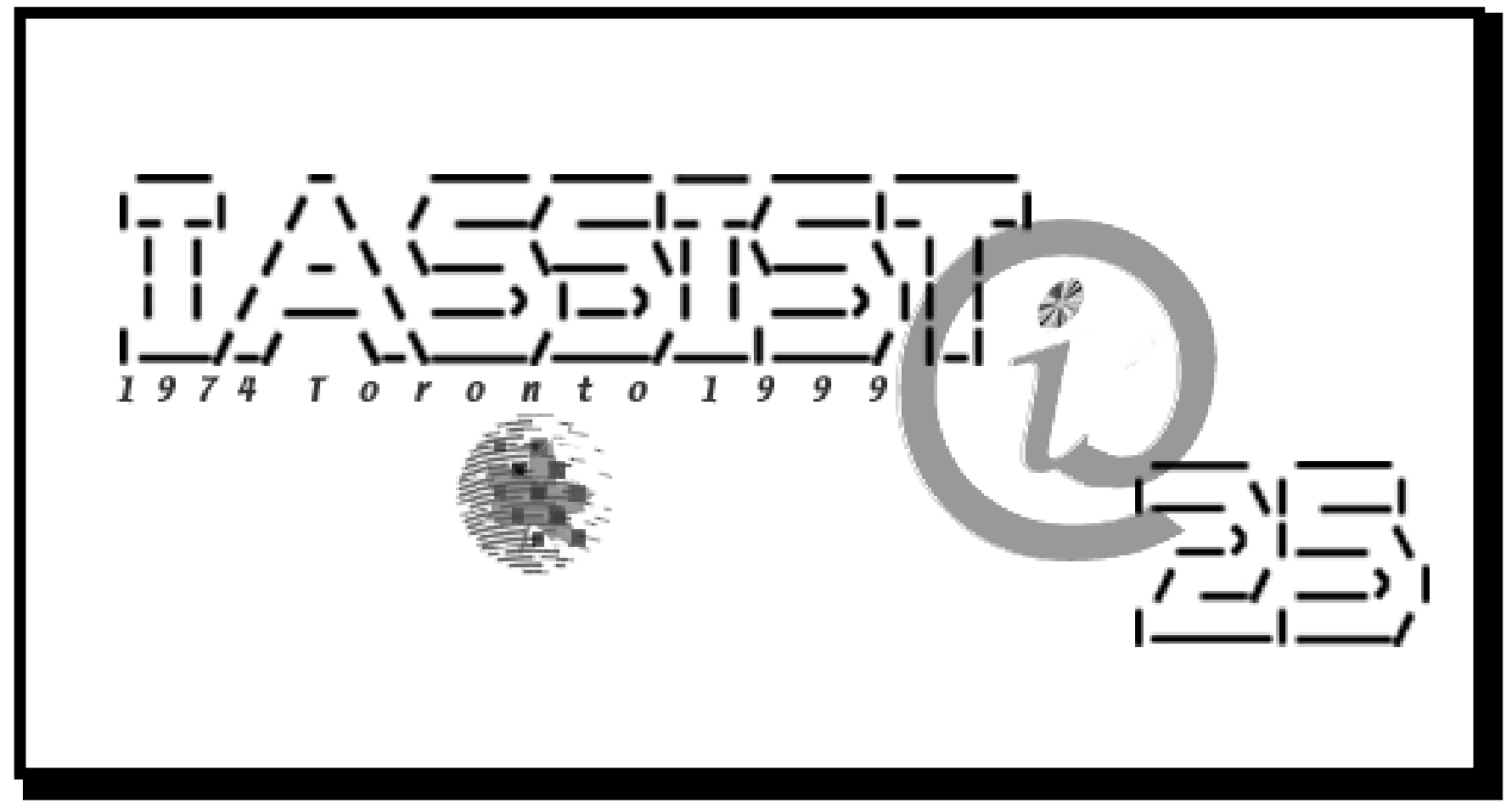

